\title{
A modo de introducción: Memoria, deseo y narración
}

\author{
April is the cruellest month, breeding \\ Lilacs out of the dead land, mixing \\ Memory and desire, stirring \\ Dull roots with spring rain. \\ (T.S. Eliot, The Waste Land ${ }^{1}$ )
}

Tras la publicación del número monográfico de nuestra revista "Perspectivas transatlánticas: Manuel Vázquez Montalbán y Latinoamérica" coordinado por José Colmeiro y Michael Aronna y antes de la próxima publicación de "En la mesa con Manolo: La gastronomía como acto cultural y político", monográfico coordinado por José Colmeiro y H. Rosi Song publicamos esta nueva recopilación de artículos.

No creemos que sea necesario remarcar el valor de los textos de Manuel Vázquez Montalbán en y para el ámbito de los estudios sobre Memoria, Historia y Narración; ya en el año 2007 José Colmeiro editó una antología: Manuel Vázquez Montalbán. El compromiso con la memoria ${ }^{2}$ en la que diversos autores trataron los temas mencionados desde diferentes enfoques mostrando la importancia y actualidad de su obra.

La cita de los primeros versos del La tierra baldía de T.S. Eliot que abre este número monográfico de la revista MVM se los apropió Manolo Vázquez para titular su obra poética Memoria y deseo. Obra en la que se condensan en forma de collage intertextual su visión de la realidad, su memoria y su deseo de transformación.

Memoria, en forma de una narración construida a partir de diversos géneros literarios y periodísticos, proyectada al futuro en forma de "mensajes de náufrago dentro de una botella". Mensajes del pasado para comprender el presente y poder afrontar el futuro. Mensajes para poder acceder a aquel "tan esperado octavo día de la semana" " que recorrerá implícitamente su obra.

\footnotetext{
1"The Burial of the Dead" en Eliot, T.S. Eliot. The Waste Land. London: Faber and Faber, 1949.

${ }^{2}$ Woodbridge, Suffolk: Tamesis Books (Boydell\&Brewer).

3“Jamboree" en Vázquez Montalbán, Manuel. Memoria y deseo. Obra poética (1963-1990). Barcelona: Grijalbo Mondadori, 1996, 59.
} 
Saber expresarse, saber poner por escrito lo que uno piensa y siente es como poder enviar mensajes de náufrago dentro de una botella a la posteridad. Cada barrio debería tener un poeta y un cronista, al menos, para que dentro de muchos años, en unos museos especiales, las gentes pudieran revivir por medio de la memoria. ${ }^{4}$

La intención de este número monográfico era la de establecer una colaboración concreta entre la Asociación de Estudios Manuel Vázquez Montalbán y la Red Internacional de Investigación y Aprendizaje: Memoria y Narración. La primera convocatoria para la recepción de artículos se anunció el 22 de junio de 2020, en los inicios de la pandemia Covid-19, con todo lo que esto supuso en y para el mundo académico.

En este número hemos recogido cinco artículos que tratan de algunos aspectos de la amplísima y calidoscópica obra de Vázquez Montalbán resaltando la perspectiva de la memoria.

El cuaderno se abre con el artículo "Carvalho en construcción: Yo maté a Kennedy" de Miquel Bota. El autor resalta el carácter iniciador de la saga de las novelas del detective Pepe Carvalho, pero muestra también su diferencia como producto experimental, vanguardista, en otras palabras su "subnormalidad" dentro del ámbito literario montalbaniano. Miquel Bota resalta la escasez de estudios sobre Yo maté a Kennedy en relación con lo mucho escrito acerca de las diferentes novelas que componen la serie de Carvalho. En su texto muestra Bota la estrecha relación en la novela entre los intereses económicos, las diferencias sociales o de clase con una visión patriarcal poco estudiada por la crítica que ha escrito sobre esa novela. Ambas dimensiones del personaje actualizan una novela escrita en 1975.

El segundo texto es de Adriana Minardi: "Leer la memoria, construir la democracia. Las crónicas sentimentales de Manuel Vázquez Montalbán". Minardi aborda el tema de la relación de las llamadas crónicas sentimentales montalbanianas con el concepto de "razón democrática".

El tercer artículo tiene como título: "Crónica sentimental del fútbol" escrito por Jordi Osúa Quintana. Jordi Osúa relaciona en su texto el fenómeno del fútbol con la cultura popular diferente de la de las élites

${ }^{4}$ Vázquez Montalbán, Manuel. El pianista. Barcelona: Seix Barral, 1985, 138139. 
sociales y culturales. La crónica sentimental del fútbol será, pues, una de las crónicas sentimentales del franquismo en forma de denuncia de la vinculación del mundo futbolístico de la época con el régimen franquista $\mathrm{y}$, a su vez, el intento de contrarrestar el olvido del fútbol como elemento constitutivo de su memoria personal y de la colectiva.

El cuarto trabajo se titula "La memoria compartida por las palabras de un transmisor de la historia: Manuel Vázquez Montalbán" y su autora es Anne Sophie Owczarczak. La autora se va a centrar en la realización de un análisis de un corpus basado en las revistas Por Favor y Triunfo y en concreto en los artículos escritos en ellas por Vázquez Montalbán durante el año 1975. Owczarczak ha presenta en su artículo los hallazgos encontrados en la realización de un análisis automático de contenido textual utilizando el programa Lexico3. La información recogida de ambas revistas es un buen ejemplo de los mencionados más arriba "mensajes de náufrago" recogidos, analizados y enviados esta vez no en botellas sino a través de los métodos de las humanidades digitales.

Y por fin este número 6 de la revista lo cierra "La identidad reelaborada en Galíndez de Manuel Vázquez Montalbán", texto escrito por Santiago Sevilla Vallejo. Aquí autor resalta la importancia en la obra Montalbaniana, y en concreto en la novela Galíndez, de la ética de la resistencia social basada en la necesidad de desvelar las estrategias manipulativas del poder y sus dramáticas consecuencias.

Creemos que a pesar de todas las dificultades generadas por la pandemia que aún estamos sufriendo, este número de MVM: Cuadernos de Estudios Manuel Vázquez Montalbán se mantiene fiel a los deseos de Andrés el personaje de la novela El pianista y de su deseo de combatir el olvido soñando con vivir un "octavo día de la semana".

La sexta conferencia de la asociación iba a tener lugar en la Universidad de Oslo durante el verano de 2021, desgraciadamente las restrictivas políticas de prevención contra la pandemia hicieron imposible su realización. 